\title{
Do vključevanja z izključevanjem
}

\section{Preobraženi rasizmi sodobnih vzgojno-izobraževalnih in socialnovarstvenih praks za »vključevanje « Romov}

\begin{abstract}
Romiso biliv Evropistoletja tarče nasilja, kaznovanja, izključevanja in patologiziranja, ssodobno, razsvetljensko prevzgojno vnemo pa naj bijim » pomagali «, da se otresejo pripisane manjvrednosti, opustijo problematična vedenja in se asimilirajo. Avtorica dokazuje, da se sodobni programi za vključevanje kljub humanističnemu pridihu in zavezanosti k varovanju manjšinskih pravic skladajo s prejšnjim strukturnim nasiljem. Pri tem v večini primerov dobrohotno »vključevanje « $\checkmark$ praksi pomeni socialno, kognitivno, jezikovno asimilacijo, za namene multikulturalizma pa so Romom prepuščene nekatere eksotizirane poteze kulture. Takšna interpretacija Rome prikazuje kot ljudstvo, katerega edini problem je, da niso dovolj napredni - vsega preganjanja in poskusov » vključevanja « so deležni le zato, ker je njihova točka razvoja nezdružljiva z evropsko civilizacijo. Nereflektirano » vključevanje «Romov, predvsems pedagoškiminsocialnoskrbstvenimaparatom, poraja noveetape izključevanja, diskriminacije in rasističneobravnave, kerohranjasimbolno mejo med Nami in Njimi čvrsto. Če prevzgoja ni učinkovita, je krivda za neuspeh projektovvključevanja pripisana Romom. Čeprav je vključevanje Romov uradno postalo imperativ, avtorica opozori na spornost nadnacionalnih in nacionalnih strategij in smernic o vključevanju, ki je v resnici samo nova preobleka izključevanja.

Ključne besede: strukturno nasilje, asimilacija, inkluzija, diskriminacija, neenakost, antirasizem.

Lucija Klun, mag. soc. kult., jeasistentka na Inštitutu zaslovensko izseljenstvo in migracije. Kontakt: lucija.klun@zrc-sazu.si.
\end{abstract}

To exclude by including - Transformed rasisms of modern educational and social care practices for »inclusion « of the Roma

The Roma in Europe have been targets of violence, punishment, exclusion and patologisation for centuries, but modern, enlightened urge to re-educate was supposed to » help « them to get rid of assigned inferiority, abandon their problematic behaviours and get assimilated. The author proves that modern programmes for incusion are, despite their humanistic flair and obligation to minority rights protection, in accordance with previous structural violence. In most cases, benevolent » inclusion «means social, cognitive, and language assimilation, but for purpuses of multiculturalism the Roma are allowed to retain some exotised cultural characteristics. Such an interpretation paints the Roma as a people whose only problem is not being progressive enough - they are subjected to all the persecution and attempts at » inclusion « only because their point of development is incompatible with the European civilisation. Unreflected » inclusion « of the Roma, mostly by means of educational and social care apparatus, produces new stages of exclusion, discrimination and rasist treatment, keeping the border between Us and Them intact. If re-education and inclusion attempts fail, now the Roma are to blame. Despite the fact that inclusion of the Roma has officially become an imperative, the author points to disputable supranational and national strategies and guidelines on inclusion, and portray them as just a new disguise of an old exclusion.

Keywords: structural violence, asimilation, inclusion, discrimination, inequality, antirasism.

Lucija Klun, MA in Sociology of Culture, is an assistant at the Slovenian Migration Institute. Contact: lucija.klun@zrc-sazu.si.

\section{Uvod}

V članku bom izhajala iz petih virov.

Prvič, izhajam iz izkušnje sodelovanja z romskimi družinami na področju Ljubljane in spontane zagovorniške pozicije v razmerju do institucij prevladujoče družbe ter iz primerov strokovnega diskurza pedagoških delavcev, s katerimi sem opravila polstrukturirane intervjuje o vključevanju Romov. 
Drugič, izhajam iz del avtorjev, ki o rasizmu v neoliberalizmu pišejo kot o fenomenu, ki ga je zaradi hitre preobrazbe vse težje zgodoviniti in kontekstualizirati (Powell in van Baar, 2019; Balibar in Wallerstein, 1998; Goldber, 2015). Poenostavljeno - netradicionalni anti-romski rasizem (ki biologizme nadomesti s kulturalizmi) se redko prepoznava kot del rasiziranega zgodovinskega razmerja neenakosti. Hkrati avtorji poudarjajo, da rasizem ni »(le) ideologija v ozkem, idejnem smislu, temveč niz institucionaliziranih praks družbene segregacije in izključevanja, kjer rasa ni izhodišče, temveč rezultat « (Krašovec, 2015, str. 10). Torej, da rasa in etnična pripadnost ${ }^{1}$ nista (biološka) podstat rasizma, ampak njegov produkt. Antiromski rasizem je tako pogoj za produkcijo »romskosti« oziroma opredeljevanja Romov kot distinktivne rasne/etične skupine. Institucionalne prakse, ki vzdržujejo pojem »Roma« in predvsem »Roma, potrebnega pomoči«, so v tem pogledu inherentno rasistične. Če podam primer: pedagoški in socialni delavci, ki so del (vladnih, občinskih, nadnacionalnih, nevladnih) projektov za vključevanje Romov, so produktivni na več ravneh: v praksi producirajo svojo lastno vlogo, vlogo rasiziranega/etniziranega objekta svojega dela; hkrati pa (ad hoc) konstruirajo idejo socialne vključenosti/izključenosti. Pri tem obidejo ${ }^{2}$ teoretske postavke, ki socialno vključevanje pojmujejo v pomenu razširjanja mej normalnosti (Zaviršek, 2003) in se osredotočijo na podporo romskim uporabnikom, da prevzamejo večinske navade in jih vgradijo v svoj (dozdevno patološki/pomanjkljiv) kulturni repertoar.

Tretjič, izhajam, iz teze, da je romski antirasizem strukturni element (gradnik) ne le negativnih institucionalnih praks (policijski nadzor, kaznovanje, urbana segregacija, kršenje človekovih pravic), ampak tudi pozitivnih institucionalnih praks (projekti socialne krepitve, vključevanja, spodbujanje razvoja, posebna obravnava, dodatna strokovna pomoč ipd.). $V$ tem pogledu bom uporabila van Baarov pojem institucionalnega developmentalizma, ki sovpada z novimi antiromskimi rasizmi (van Baar, 2018, 2019).

Institucionalni developmentalizem je neomodernistični pogled, ki predpostavlja, da se bodo »nerazviti« Romi po zaslugi razvojnih projektov in pobud, namenjenih inkluziji, participaciji, krepitvi moči, zagotavljanju človekovih in manjšinskih pravic in krepitvi skupnostih virov, postopno pridružili evropskim »razvitim« večinam. (van Baar, 2019, str. 160)

Četrtič, izhajam iz del avtorjev, ki ugotavljajo kontinuiteto, ne pa prelom med zgodovinskimi (po večini negativnimi) in sodobnimi (po večini pozitivnimi) institucionalnimi praksami »upravljanja z Romi«. Olivera (2012, str. 40) zapiše:

Iz daljše zgodovinske perspektive lahko na romsko vprašanje gledamo kot na neposrednega dediča ciganskega problema, ki se je v zahodni Evropi pojavil na začetku prejšnjega stoletja. Ciljna »publika« ostaja ista (»te različne skupine, ki so iz Indije prišle v Evropo na koncu srednjega veka«) in predstavlja »izziv«, ki naj si ga večinske družbe zastavijo: Kako vključiti/ integrirati Rome/Cigane?

1 Antropologi danes pojem rase načelno zavračajo in raso razumejo kot vidik etničnega razlikovanja (Šumi, 2000).

2 S tem ne ciljam na slabonamernost pedagoških in socialnih delavcev - njihove pristojnosti pogosto ne presegajo ozkih ciljev integracije/asimilacije. 
Vprašanje ostaja enako, spreminjajo pa se odgovori: »ciganski grožnji « prejšnjih stoletij so ustrezale represivne rešitve - institucionalna vloga je bila negativna v pomenu preganjanja in eksplicitnega nadzora - »romskemu vprašanju« pa ustrezajo politike vključevanja - institucionalna vloga je pozitivna v pomenu »integracije, manjšanja primanjkljajev in omogočanja enakih možnosti« (Krek, 1995), reševanja Romov iz »pasti odvisnosti« (UNDP, 2002) in iz »začaranega kroga revščine« (Ringold, Orenstein in Wilkens, 2003), prizadevanja za »zapiranje vrzeli med Romi in Neromi« (Evropska komisija, 2014, str. 7). Obrat se začne z razsvetljenstvom (Mayall, 2004), ko zatiranje nadomesti ideja, da je mogoče Rome/Cigane prevzgojiti v uporabne pripadnike družbe. Ta pojem ima sprva modernistično konotacijo ekonomske uporabnosti, saj »upravičuje« izkoriščanje in prekaren status romskih delavcev. V poznem 20. stoletju - van Baar (2018) developmentalistično agendo umesti v obdobje po letu 1989 - pa se ideja razvoja postmodernizira:

Zgodi se pomik od prej prevladujočih idej o modernizaciji, ki jo vodi država, predvsem na podlagi gospodarske rasti [...] in to nadomesti ideja razvoja, utemeljenega na izboljšanju zdravja, izobraževanja, zaposlovanja, socialne inkluzije ... (Duffield in Waddell, 2006, str. 44)

Petič, opiram se na avtorje, ki uvajajo pojem developmentalizma in so do procesov, ki jih prepoznavajo s tem imenom, kritični. Gre za sklop potez diskurza o Romih, od zgodnjih esencializmov (slovenske) romologije do diskurza evropskih dokumentov, ki postkolonialna zrkla v devetdesetih obrnejo od »družb v razvoju globalnega juga « $\mathrm{k}$ »segmentom sveta v razvoju znotraj evropskih družb, ki jih v večini predstavljajo Romi« (UNDP, 2002, str. 21, moj poudarek). V prvem primeru (predstavnik je npr. Šiftar, 1970) gre za arhetipsko reprezentacijo Romov, ki se opira na ljudski imaginarij o »dimu, ognju, vročekrvnih ženskah « (Janko Spreizer, 2001, str. 31), in za teoretizacijo skupnega biološkega izvora (vseh) Romov, to pa spremljajo navedbe, da bodo morali - kot skupina - še prehoditi družbeno-razvojno pot $^{3}$. V drugem primeru pa gre za diskurz (napredka in razvoja), vendar se ne napaja iz biologiziranih esencialističnih predstav, ampak iz diskurza o človekovih pravicah, manjšinskih pravicah, enakosti, multikulturalizmu in blaginji.

Podobno kot postkolonialni razvoj [...] postsocialistični pojem razvoja, namenjen evropskim Romom, v zadnjih dveh desetletjih temelji na ideji postopnega napredka in razvojnega kontinuuma. Romi naj bi bili na enaki razvojni poti kot »mi«, »razviti« Evropejci, pri tem pa »oni« za zdaj še zaostajajo. Ta problem je mogoče rešiti le, če prehodijo podobno pot - skozi številne etape socialno-ekonomskega in človeškega razvoja, da se nazadnje povežejo z »našo« moderno, tekmovalno, multikulturno in poenoteno Evropo. (van Baar, 2019, str. 173, moji poudarki)

Developmentalistične predpostavke vodijo v biopolitizacijo - vprašanja o inkluziji Romov niso več ekonomska, ker se vidiki razvoja zožijo na »zaželen

3 Ta diskurz so prepričljivo kritizirali socialni antropologi (v Sloveniji Janko Spreizer) in sodobnejši avtorji romoloških študij (npr. Lucassen, Willems in Cottard, 1998), ki so epistemološko zarezali v to ( $v$ » znanost « pretopljeno) esencialistično vednost o ljudeh, ki ustrezajo podobi »resničnih Ciganov«. 
način življenja « (van Baar, 2019, str. 174), na samozadostnost individuuma in ožje romske skupnosti: »Ti programi se osredotočajo na biopolitične dispozicije Romov namesto na njihove socialno-ekonomske življenjske razmere« (van Baar, 2019, str. 174).

Takšni diskurzivni zasuki vodijo v pojav »liberalnega intervencionizma« (Duffield, 2010), se pravi v legitimizacijo intervencij v populacije, ki so označene kot nerazvite. Intervencija se zdi nujna, saj morajo (s podporo/pomočjo ali prisilo držav, občin, institucij, nevladnih organizacij) nosilci nerazvitosti izboljšati svoj življenjski standard in položaj ter s tem uresničevati idejo evropske blaginje in (delujočega) multikulturalizma. Poenostavljeno: odgovornost za uresničevanje strateških aspiracij se prenese na lokalne izvajalce (šole, vrtce, centre za socialno delo) in romske skupnosti same.

Opisana epistemološka izhodišča so okvir, v katerem nastaja članek. Pri tem ne gre zanemariti, da - ko pišem o Romih - mislim na različne skupine in posameznike znotraj držav in lokalnih skupnosti, ki so jih večinske družbe kategorizirale s krovnim pojmom. A kljub svoji različnosti doživljajo podobno obravnavo (sploh pod okriljem EU).

\section{Nekatere poteze » upravljanja z Romi « v Evropi}

Liégeois in Gheorghe (1995) politike, ki so jih evropske države v zgodovini uporabljale za upravljanje s Cigani/Romi, delita na tri kategorije: izključevanje, omejevanje, vključevanje. Opisala bom vsako od treh, potem pa bom pozornost namenila sodobnim mehanizmom upravljanja z Romi, ki se uvrščajo v kategorijo »vključevanja« v dominantno družbo. Pri tem v večini primerov »vključevanje« v praksi pomeni socialno, kognitivno, jezikovno asimilacijo, za namene multikulturalizma pa so Romom prepuščene nekatere eksotizirane poteze kulture (v nekaterih primerih celo kulturne »invencije«), ki naj bi jo gojili in ohranjali (ples, igranje na glasbila in pisana oblačila).

Zgodovina izključevanja obsega poskuse, da bi Cigane/Rome (ponekod poenotene tudi z oznako poganov, Saracenov, Tatarov) iztrebili ali pregnali z ozemlja. Prvi anticiganski zakon je bil v nemški deželi sprejet leta 1439, v Franciji 1452, sledile so Švica leta 1471, Portugalska in Nizozemska leta 1526 ter Danska leta 1536 (DiRicchardi-Muzga, 2011). V Franciji je bila leta 1510 njihova navzočnost na ozemlju kaznovana z obešanjem (Liégeois in Gheorghe, 1995). V nemških deželah so jih obravnavali kot izdajalce krščanstva, turške vohune in prenašalce kuge (ibid.). V Italiji so jih obtoževali za shizme, papež Pij V. jih je leta 1568 izobčil iz katoliške cerkve (DiRicchardi-Muzga, 2011). Leta 1721 je Karel VI. v Franciji na smrtno kazen obsodil vse odrasle moške Rome, za ženske in otroke je odredil, da jim odrežejo uho (Liégeois in Gheorghe, 1995). In v nacistični Nemčiji je bilo usmrčenega vsaj pol milijona Romov.

Kot politike omejevanja Liégeois in Gheorghe (1995) obravnavata obvezno, večinoma nasilno asimilacijo s ciljem, da bi postali nevidni - z omejevanjem svobode in pravic, razseljevanjem in drugimi sredstvi, ki naj jih prisilijo $\mathrm{v}$ konformizem in »družbeno uporabnost«. Najnazornejši primer »omejevanja« je bilo množično zasužnjevanje v Romuniji od 14. stoletja: Rome si je lastil 
kler, država ali premožne rodbine; prodati jih je bilo mogoče na dražbah ali pokloniti v dar. V Avstro-Ogrski sta od srede 18. stoletja »ciganske/romske politike« vodila Marija Terezija in za njo Jožef II. Pripisujejo jima prve civilizacijske poskuse, »utemeljene na razsvetljenski misli o možnosti prevzgoje ljudi« (Ivanov in Medved, 2006, str. 76). Prepovedala sta nomadizem in si prizadevala, da bi jih preobrazila $\mathrm{v}$ »produktivno prebivalstvo, ki plačuje davke in služi vojsko « (Repič, 2006). Ko ti ukrepi niso zalegli, so jim odvzeli vse otroke, starejše od pet let (Jožef II. je to politiko poostril na štiriletne, po nekaterih virih celo na dvoletne otroke), in jih dali v rejo zglednim družinam ali duhovnikom (Šiftar, 1970).

V drugi polovici 20. stoletja so uvedli politike vključevanja. Zaradi humanističnih idej so oblastniki opustili telesno kaznovanje in fizično prisilo, prepovedali suženjstvo in neupravičene odvzeme otrok (Liégeois in Gheorghe, 1995). Moderne države so namesto tega prevzele tehnokratske modele vodenja družbe. Iz navedenih sprememb je izšel moderen način »obravnave« romske populacije: »vključevanje« s ciljem postopne »družbene absorpcije Romov« (prav tam, str. 10). V novem režimu so definirani predvsem kot odpadniki in marginalci, njihove preostale »drugačnosti « (popotništvo, ekonomska nepodredljivost ipd.) pa so dobile simbolno oznako »socialnih in psihičnih težav«. Tako so se »kulturna vprašanja spremenila v socialni problem « (prav tam, str. 10). Zakonodajno se nov pristop regulacije na evropskem področju uresničuje predvsem s pomočjo socialnoskrbstvenega sistema ter sistema vzgoje in izobraževanja:

Nadzor je tako bolj human, ampak tudi bolj vseobsegajoč - in v sklopu politike »absorpcije« deluje v smeri »normalizacije« vsega, kar je percipirano kot marginalno in deviantno. (Liégeois in Gheorghe, 1995, str. 10)

V šestih stoletjih ${ }^{4}$ so evropske politike »upravljanja« s Cigani/Romi nadomestile oblastniške postopke, vsem pa je skupno, da so jih oblasti upravičevale s pregovorno romsko manjvrednostjo in grožnjo obstoječim normam (Fraser, 1995). Repič (2006) prepoznava, da je v vsaki zdajšnji interakciji med Romi in institucijami večinske družbe opaziti jasno kontinuiteto pretekle obravnave oblasti.

\section{Lokalni izvajalci nadnacionalnih strategij vključevanja}

Skupine Romov so bile v preteklosti tarče kaznovalnih organov, danes pa so (predvsem) objekt socialnih in pedagoških delavcev (gl. Trubeta, 2013). Strokovnjaki delujejo glede na cilje vključevanja, ki jih diktirajo nadnacionalne in nacionalne strategije in smernice (na primer Strategija vzgoje in izobraževanja Romov v Republiki Sloveniji ${ }^{5}$, 2004; Strategija EU o vključevanju Romov, 2011), in glede na - pogosto nenapisana - pravila vključevanja Romov v lokalnih

4 Razločevanje ciganskih skupin se je začelo že pred 14. stoletjem, kar pokažejo npr. Fraser (1995), DiRicchardi-Muzga (2011), Lucassen, Willems in Cottard (1998).

5 Pripravila jo je delovna skupina za pripravo strategije vključevanja Romov v vzgojo in izobraževanje. 
okoljih in ustanovah ${ }^{6}$. V nekaterih vrtcih in šolah to pomeni vključevanje $\mathrm{v}$ posebnih romskih oddelkih, $\mathrm{v}$ drugih individualno in skupinsko pomoč, $\mathrm{v}$ tretjih zgodnje usmerjanje romskih otrok kot otrok s posebnimi potrebami.

Vključevanje Romov je imperativ, izvedba v domeni strokovnih delavcev. Da bi vedeli, kako Rome vključevati - pa morajo sprva poznati konstrukt/ pojem socialno izključenega Roma, pripadnika ranljive družbene skupine, ki mora biti obravnavan s posebno vnemo. Zaviršek (2018) opozarja, da neoliberalni besednjak nakazuje, da je izključenost/ranljivost nekaj imanentnega »tem ljudem«, čeprav gre za osebe, ki »niso ranljive same po sebi, temveč jih ranljive dela nasilni kontekst, ki se pogosto kaže kot skrb zanje« (Zaviršek, 2018, str. 15). Romi so v kontekstu intenzivirane skrbi in vzgoje v zadnjih desetletjih gotovo ranljivi - predvsem zato, ker imajo malo besede $v$ konstrukcijah lastne ranljivosti in (pre)malo besede pri reševanju te. A vsi ti manevri »vključevanja« so posebej problematični, ker so iztrgani iz širšega konteksta in jih strokovnjaki izvajajo:

i. brez razumevanja zgodovinskega konteksta nastanka romskih etničnih skupin in brez razumevanja zgodovine zatiranja in diskriminacije ter brez razumevanja zgodovine poskusov »romski odklon« popraviti in asimilirati,

ii. brez razumevanja konteksta družbene neenakosti v kapitalističnem sistemu in reproduktivne narave institucij - Romi niso »le« etnična manjšina, katere marginaliziranost je moč odpraviti z merico multikuluralizma ${ }^{7}$, ampak so tudi zgodovinski "podrazred« brez dostopov do materialnih sredstev in brez dostopa do virov moči;

iii. - s postopki pedagogizacije in intervencij $v$ življenjski slog,

- s paternalistično obravnavo in infantilizacijo Romov, ki dozdevno potrebujejo pomoč pri socializaciji in razvoju,

- s patologizacijo Romov ${ }^{8}$ (pripisovanje duševne manjše razvitosti, obravnavanje romskih otrok kot otrok s posebnimi potrebami, merjenje in popravljanje »primanjkljajev«) (gl. Zaviršek, 2010),

- s kulturalizacijo potez »romskosti«, ki so v resnici (so)produkt revščine in socialne izključenosti,

- s tradicionalnim in kulturnim rasizmom,

- z biopolitičnimi manevri, ki povsem prevladajo nad socialno-ekonomskimi/materialnimi intervencijami (na primer v smeri večje enakosti $v$ dohodkih, nastanitvenem standardu) in so primarno namenjeni temu, da »ohranjajo in vzdržujejo generično biopolitično ločnico med razvitimi in nerazvitimi« populacijami (Duffield, 2010, str. 66)

Začetna vnema strokovnih delavcev se zaradi opisane »zgoščenosti« problematike postopno spremeni v izgorelost. Takrat obupujejo nad romsko »svoje-

6 Gre za lokalne ideje, kako Rome vključevati; pa tudi za mnogoštevilne projekte, ki jih z Romi v mislih prijavljajo vrtci, šole, občine, nevladna društva (npr. Projekt skupaj do znanja, b. d.; Strategija reševanja romske problematike v Občini Krško za obdobje 2018-2022, 2018; Uspešno vključevanje Romov v vzgojo in izobraževanje, 2012).

7 Dragoš (2005, str. 41) je zapisal, da multikulturalizmu uhaja prav tisto, kar določa njegovo dinamiko: »družbena struktura in razmerja moči, v katerih se etnije razvijajo in izginjajo. «

8 Gl. tudi: Zaviršek in drugi (2019, str. 10), kjer podrobno opredelijo pojem patologizacije Romov. 
glavostjo« in nepripravljenostjo na spremembe. Tudi ti občutki so del zgodovinske kontinuitete; najti jih je na primer v Brochausovem zapisu (Der Grosse Brockhaus, 1935, 20. zvezek, v Boljka in Krnjić, 2006, str. 43), da »niti krvavi pregoni niti dobronamerna civilizacijska prizadevanja ... niso mogli spremeniti narave Ciganov ali zmanjšati njihovega števila.« V sodobnosti imajo pritožbe blažjo konotacijo:

Vsakodnevne izkušnje pri delu z Romi kažejo, da so ujeti v začaran krog, zadovoljni so z doseženim, starši niso vsakodnevno pripravljeni pomagati svojim otrokom pri domačih nalogah, pri branju in učenju, niso motivirani, da bi otroci dosegli višje cilje, višjo izobrazbo in s tem boljši socialni položaj. (Gjerkeš Ščančar, 2016, str. 134)

Darja Zaviršek (2010) piše o vključevanju s pomočjo izključevanja (pri tem izhaja iz Agambna ${ }^{9}$, 2013), jaz pa predlagam nasprotno sintagmo: izključevanje s pomočjo vključevanja. Tako je mogoče pokazati, da prav silna »vključevalna« prizadevanja in prenos odgovornosti na Rome (ko so prizadevanja neuspešna) poganjata mehanizme diskriminacije in rasizma. Sodobni governmentalistični prijemi za Rome so manj odkriti, a kljub temu gre za udejanjanje družbene premoči večine nad manjšino. Najprej proizvedejo podobo Roma, ki mora biti vključen (pri tem imajo Romi malo ali nič besede), in s tem naredijo biopolitično brazdo med Nami in Njimi, nato pa ob neuspehu projektov »vključevanja« krivdo pripišejo Romom. Sodobni prijemi morda zarežejo še odločilneje, ker niso represivni in je strukturno nasilje težko opaziti pod (povsem realno) dobrohotnostjo strokovnjakov.

V članku bom poskusila razkleniti epistemološki dvojec »romski problem« - »rešitev Romov/za Rome«. Potem bom pokazala še, da so sodobne politike del že opisane zgodovinske kontinuitete ${ }^{10}$. Pokazala bom, da antagonizem vključevanja/izključevanja poganja predpostavka o romskem »kolektivnem zaostanku « (v nekaterih primerih je ta izrečena, v drugih pa implicitna) - kot etnična skupina se zdijo ujeti v drugem času in prostoru - nečasu in neprostoru, zunaj družbenega časa večinske skupnosti in hkrati tudi zunaj zgodovin nacionalnih držav.

\section{Diskurz razvoja: Romi kot homines educandi ${ }^{11}$}

Razsvetljenstvo je pomenilo ideološki pomik (najopazneje v avstro-ogrskih politikah prevzgoje): Romov ne kaže le preganjati, ob vztrajnih intervencijah je mogoče »iz teh podložnikov ustvariti prave ljudi in državljane«, kot je upala Marija Terezija (Boljka in Krnjić, 2006, str. 42). Razsvetljenstvo je izumilo

9 Oziroma - zapisano drugače, njegov koncept »inclusive exclusion « obrnem v » exclusive inclusion «.

10 Sodobni strokovni diskurz o Romih bom ponazorila z odlomki iz strokovnih in znanstvenih člankov, diplomskih in magistrskih nalog in deli intervjujev, ki sem jih leta 2019 opravila s pedagoškimi delavci. Intervjuje sem izvedla v treh ljubljanskih vrtcih, dveh osnovnih šolah in dveh podružnicah osnovne šole s prilagojenim programom, ki jih obiskujejo Romi. Intervjuje sem transkribirala, kodirala, kategorizirala in analizirala kot kvalitativne podatke.

11 Naslov si sposojam od avtorice Sevasti Trubete (2013), ki ga uvaja v svojem besedilu Roma as homines educandi. 
izobraževanje kot mehanizem za kulturni razvoj najnižjih socialnih slojev (Young, 1995). Idejno je izhajalo iz hipotetične egalitarnosti: enakost sicer ne obstaja v sedanjosti, ampak z možnostjo (pre)vzgoje je vsak potencialno enak drugim. Ključne institucije, ki lahko neenakost spremenijo v enakost (možnosti), so vzgojno-izobraževalne. V tem kontekstu so vsi nižji sloji, še posebej pa etnične manjšine, v zahodni Evropi postali homines educandi (Trubeta, 2013) - skupnost tistih, ki (kot kolektiv in posamezniki) zaostajajo, naloga držav pa je, da zaostanek odpravijo. Poleg tega se vračamo k že vpeljanim konceptom »developmentalizma « in »liberalnega intervencionizma«, pri tem pa prvi nakazuje »kolonializem zahodnih družb«, ki odkrijejo Rome kot »notranji nerazviti element « in iz njih naredijo »največji evropski razvojni projekt po letu 1989« (van Baar, 2018, str. 447). Razvojna dogma oznanja kolektivni proces, ki naj bi celotno etnizirano skupino dvignil na primerno raven. A pojem »razvoja« ima tudi druge, bolj mikrosocialne (v pomenu primarne socializacije) in individualne konotacije: gre za »biopolitizacijo« (Duffield, 2007). Pri tem je namen oblasti in njenih institucij izboljšati »biopolitične lastnosti na ravni posameznika in skupnosti« (van Baar, 2019, str. 73).

Za namen tega članka bom o »razvoju« pisala v treh pomenih. Gre predvsem za poskus pokazati, kako splošen pojem razvoja pronica vse globje z makroravni evropskih družb na nacionalno raven in raven lokalnih skupnosti, romskih družin in posameznikov. Tako ima biopolitična oblast, obdana z diskurzom varovanja človekovih in manjšinskih pravic, moč s svojimi mehanizmi doseči vse družbene kotičke in robove. Hkrati pa se lahkotno vpne v vsakdan pedagoških, socialnih in zdravstvenih delavcev.

Razvoj torej koncipiram trojno:

1. najprej kot razvoj otroka, kakor ga obravnavajo razvojna psihologija in vede, ki se osredotočajo na individualno obravnavo otrok (npr. specialna pedagogika, logopedija);

2. razvoj kot»strukturirano spreminjanje lokalnega (primarnega) otrokovega okolja « (Katz, 2004, str. x) in hkrati možnost »izboljšav« dispozicij otrokovega zgodnjega okolja (sem sodijo šole za romske starše, spodbude strokovnih delavcev, da bi romski starši bolje vzgajali otroke, bolj kakovostno komunicirali z malčki ipd.);

3. razvoj celotne etnične skupine v širšem pomenu, predvsem izhajajoč iz postkolonialističnih študij (že omenjeni pojem developmentalizma, po katerem naj bi Romi z institucionalno podporo razvojno »lovili« preostalo družbo; npr. van Baar, 2019).

Vse tri razvoje je povezala že Burman (2008) v knjigi Razvoji: otrok, podoba, narod, predvsem $\mathrm{v}$ pomenu povezovanja razvojne psihologije s postkolonializmom. Domnevni razvojni zaostanek Romov je konstruiran na vseh treh ravneh:

1. Individualni primanjkljaj: kot individualni razvojni in kognitivni zaostanek romskih otrok, ki ga je mogoče izmeriti na standardiziranih psiholoških testih. Gre za vse poskuse, ko se s »formalno patologizacijo« rešuje »težave«, povezane z jezikovnim, socialnim, kulturnim in ekonomskim ozadjem otroka. Na primer: otrokom namesto ur slovenskega jezika pripade 
logopedska obravnava, ob nerazumevanju in ponavljajočih se neuspehih je ugotovljena motnja $v$ duševnem razvoju, otrok je premeščen v osnovno šolo s prilagojenim programom.

2. Skupnostni primanjkljaj v ožjem pomenu - ta naj bi bil opazen v primarnem okolju otrok (družina, romska skupnost). Ni povsem dorečeno, ali ta deficitarnost izhaja iz pomanjkljive »romske kulture«, ki ne ponuja razvojne stimulacije, ali iz primanjkljaja, ki ga imajo starši sami (ki ga otrok "podeduje«, biološko ali s socializacijo). Prvi dve kategoriji epistemološko temeljita na razvojni psihologiji.

3. Skupnostni primanjkljaj v širšem (zgodovinskem) pomenu - kot etnična skupina naj bi Romi zaostajali za civilizacijo, zato morajo (po stališčih nekaterih avtorjev) še prehoditi družbeno-razvojno pot. V to kategorijo sodi »institucionaliziran developmentalizem«, o katerem piše van Baar $(2018,2019)$.

Prvi dve ravni sta tesno soodvisni: deficit je »izmerljiv«/opazen pri otroku, vendar izvira iz deficitarnega primarnega okolja - redkeje je zaslediti, da primanjkljaj izhaja iz otrokovih genskih predispozicij. Romsko okolje je prikazano kot pogubno za razvoj otroka: ne le, da ga ne spodbuja, ampak razvoj celo zavira in onemogoča. Novak (2006, str. 274, poudarki moji) našteva, kako romsko okolje zaznamuje otroka:

Pomembnejše determinante $\mathrm{v}$ vzgoji in izobraževanju romskih otrok, ki izhajajo iz romskega naselja Brezje, kažejo na neugodno okolje. Najbolj ovirajo otrokov normalni razvoj naslednji dejavniki: - pomanjkljivi govorni in jezikovni vzorci v romskih družinah zavirajo otrokov intelektualni razvoj; - otroci, ki živijo v manj ugodnem okolju, imajo manj izkušenj o svetu in življenju in manj možnosti za reševanje miselnih problemov v primerjavi $\mathrm{z}$ otroki iz ugodnega okolja, [...] - okrnjen moralni razvoj in nepoznavanje pravil življenja. Vzgojna zanemarjenost, ki jo opažamo v romskih oddelkih v predšolskem obdobju, pomeni za otroka konkretno in nepopravljivo posledico. Otrok, ki v tem starostnem obdobju ni primerno socialno stimuliran, se pozneje zelo težko vključuje v širše okolje.

$\mathrm{V}$ diplomskih nalogah se pojavlja podobno prepričanje:

Otrok v romski družini ni deležen spodbud, ki bi ga dodatno motivirale in prispevale k razvoju njegovih sposobnosti in intelektualnemu razvoju. [...] Neugodno okolje, v katerem živijo, je polno dejavnikov, ki ovirajo normalni razvoj. (Miladić, 2012, str. 29)

Pri Romih se vzgojna zanemarjenost pojavi v vsakem okolju, v katerega se vključujejo. Zaradi subkulture staršev otroci ne razvijejo svojih sposobnosti. (Sovič, 2010, str. 44)

Merhar (2016, str. 61-62) nespodbudnost povezuje s težavami »romske kulture«:

Romska kultura je pretežno konkretna in preprosta in ne omogoča razvoja otrokovih dispozicij. [...] Manj spodbudno okolje otroka pahne v brezno pomanjkanja spodbud za otrokov vsestranski razvoj (telesni, duševni in socialni). Otroci ne razvijejo svojih dispozicij in so posledično z vstopom v izobraževalni sistem v precejšnjem zaostanku.

V zadnjem primeru je romska razvojna zaostalost konstruirana širše. Ne le kot problem nekakovostne vzgoje ali posameznih otrok, ki ne dohajajo vrstnikov, 
ampak kot problem etnične skupine v zgodovinskem pogledu. Romi iz tega zornega kota kolektivno zaostajajo: lovijo Zahod (Ferguson, 2012). Pri tem so Romi iztrgani iz konteksta. Spregledano je, da njihova zgodovina od konca srednjega veka poteka $v$ času in prostoru preostalih evropskih narodov - da so se kot etnija izoblikovali prav »na robu« Evrope, ki jih je skušala eliminirati. Takšna interpretacija Rome prikazuje kot ljudstvo, katerega edini problem (v Evropi) je, da niso dovolj napredni - vsega preganjanja in poskusov »vključevanja « so deležni le zato, ker je njihova točka razvoja nezdružljiva z evropsko civilizacijo. Ko se zgodi ta bistroumen zasuk, se utrdi ideja, da je edina možnost, da Romi postanejo del »Nas«, da jih z disciplino, pedagoškimi prijemi in humanistično skrbjo privedemo do kognitivnega, vedenjskega in kulturnega standarda »zahodnih družb « (zdi se, da Romi še niso del teh družb). Romi so konstruirani kot ljudstvo, ki je na poti, ujeto v liminalnem prostoru med tujostjo in domačnostjo, hkrati pa na poti »razvoja « med barbarstvom in civilizacijo:

Zdi se, kot da je to ljudstvo na poti svojega razvoja doseglo šele stopnjo otroka in da so mu oči obrnjene bolj k začetku kakor h koncu, kot da je samo nekaj korakov daleč do zibelke. (Tancer, 1994, str. 149)

Intervencija v ta problemski amalgam in kompenzacija za »večslojni deficit« potekata predvsem na ravni individuuma in ožje skupnosti. Pedagoški in socialnoskrbstveni aparat tako fokus zožita na romskega otroka in njegove starše (in še nanje predvsem zato, da bi prek njih dosegli napredek pri otroku). Ideja temelji na prizadevanju za individualizacijo, ki jo je prinesel neoliberalizem. Rešitev je dozdevno v vzvratni kavzalnosti s problemom:

i. Problematika se poraja takole: zgodovinsko preganjana etnizirana skupina $\rightarrow$ sodobna romska manjšina, ki je v vseh pogledih prikrajšana in marginalizirana $\rightarrow$ romski otroci so tujejezični, njihov razvoj nima identičnega poteka kot razvoj večinskih vrstnikov (imajo znanja, spretnosti, strategije spoprijemanja s svojim okoljem) $\rightarrow$ otrok je v šoli neuspešen, na psiholoških testih je ugotovljen »primanjkljaj« $\rightarrow$ otrok dobi podporo vzgojitelja, učitelja, razvojne ambulante, specialnega pedagoga, psihologa, celo psihiatra, da mu »pomagajo « pri »vključevanju« in pri premagovanju (zgodovinsko določene, socialno-ekonomske) deprivilegiranosti.

ii. Rešitev se izvaja v smeri: intenzivno delo $\mathrm{z}$ otrokom, kompenzacija za primanjkljaj, regulacija družinskega okolja $\rightarrow$ otrok bo zrasel v boljšega starša, ki bo prekinil začaran krog revščine $\rightarrow$ romska skupnost se bo povzpela iz mrakobnega stanja revščine, segregiranosti in razmer, v katerih so jim kršene človekove in manjšinske pravice.

Rešitev za strukturni in zgodovinski problem (neenakosti) je torej v posamezniku in njegovih naporih, da se konvencionalno razvije in priuči normalnosti. Romski otroci so tako videni kot nosilci prihodnjega razvoja skupnosti. Ideje se skladajo z ekonomskimi teorijami o zgodnji investiciji v človeški kapital, ki se dolgoročno obrestuje (Burman, 2008). Skoraj vsakršen poseg je zaradi dobrodušnih aspiracij upravičen. Šolski upravnik Osnovne šole Kupšinci je leta 1956 zapisal (Janko Spreizer, 2002, str. 193): 
Zato predlagamo, da bi bilo mogoče prevzgojiti cigane in vzgojiti njihove otroke, če bi ljudska oblast za nje postavila higienske barake in predšolske ustanove, v katerih bi se dvignili na področju higiene, vzgoje in izobrazbe. Ciganske otroke, ki bi si že v predšolskih ustanovah pridobili nekaj lepih navad in se naučili slovenskega jezika, bi vključili v Osnovno šolo in jih združili s kmečkimi. Na ta način bi se polagoma absorbirale njih slabe strani razen rasti oz. razvoja (prirastek ciganov bi bil vedno večji).

V sodobnejših kontekstih se na romskega otroka večinoma osredotočajo s poudarjanjem nujnosti zgodnje institucionalizacije, individualne strokovne pomoči, s posebnimi »romskimi« spremljevalci (ti so v najboljšem primeru romski pomočniki, vse pogosteje pa specialni pedagogi), segregiranimi oddelki in usmerjanjem romskih otrok kot otrok s posebnimi potrebami - vse to $\mathrm{v}$ imenu »pospeševanja razvoja« Romov. V intervjuju je ravnateljica vrtca navedla prednosti odločbe o posebnih potrebah za romske otroke, ki omogočajo več »razvojne podpore« znotraj vrtca:

Dejansko tudi če otrok dobi odločbo, je kasneje lahko nima več. Gre res samo za to, da je bolj konstantna individualna podpora, ena na ena, strokovna, specialna, da se podpre razvoj tam, kjer je treba s specifičnimi metodami in pristopi, ne? Ne moreš ti znotraj skupine, ti ga lahko vključiš in tako, ampak oni rabijo več spodbud. Zato, ker dejansko imajo toliko primanjkljajev, niso na isti stopnji kot ti, ki so pač v normalno živečih družinah, ki imajo veliko spodbud iz spodbudnega okolja. Veliko takih izzivov ... pa tudi kultura je druga. (Intervju, 2019b, poudarki moji)

Svetovalna delavka v osnovni šoli pa je prikazala, kaj otroci pridobijo, če se šolajo v prilagojenem programu:

Meni se zdi, da oni potem lahko s tem te primanjkljaje nadoknadijo, ker imajo več spodbud, več prilagoditev, nižje standarde in so lahko dejansko samostojno uspešni, in to se meni zdi ključno veliko bolj kot v rednem programu. (Intervju, 2019a)

Po drugi strani pa se poskuša z regulacijo romskih staršev - redko z materialno podporo, pogosteje $\mathrm{z}$ »učenjem o dobrem materinstvu«. Primer takega poskusa, da bi romske matere naučili bolje vzgajati otroke, opiše Koretič (2007, str. 5, poudarki moji):

V šolskem letu 2004/2005 je bila po predlogu Pedagoškega inštituta v okviru aktivnosti projekta organizirana »materinska šola«. Z namenom graditi zaupanje med starši in vrtcem smo 2-krat mesečno še posebej vabili v vrtec romske mame z otroki. [...] Skušale smo jih osveščati o pomenu vrtca in pravilne nege za njihovega otroka. Obisk na srečanjih je bil na začetku na žalost odvisen od obljubljenih daril. Ko smo postopoma zmanjševali darila, se je tudi obisk zmanjšal. [...] Vse to kaže na to, da so Romi navajeni brezpogojno sprejemati, a jih počasi učimo tudi odgovornosti in sprejemanja obveznosti do svojih otrok.

\section{Namesto sklepa: izključevanje s pomočjo vključevanja?}

Sodobni programi se - kljub humanističnemu pridihu in zavezanosti k varovanju manjšinskih pravic - skladajo s strukturnim in simbolnim nasiljem, ki 
ga družbena skupina $\mathrm{z}$ večjo močjo izvaja nad tisto, ki nima dostopa do virov moči in je zgodovinsko marginalizirana. Poleg tega je takšno nasilje (odeto $\mathrm{V}$ humanitarizem, skrb, pomoč ranljivi skupini) implicitno in negira možnost konstruktivnega upora. Ko dani mehanizmi »kompenzacije« romskih primanjkljajev odpovedo, pa je rešitev - več istega. Le z večjo intenzivnostjo in s sporočilom: poleg Nas imajo tudi Oni odgovornost za lastno inkluzijo in vzdrževanje lastne enakopravnosti. Takole je na primer leta 2014 svoj poziv ubesedila Viviane Reding, takratna evropska komisarka za pravosodje, temeljne pravice in državljanstvo (Fejzula, 2019, str. 2014-2015, poudarki moji):

Vsi vemo, da romske situacije ne moremo rešiti v nekaj tednih, v nekaj mesecih. Potrebujemo pa resnično predanost, ne le držav članic, ampak tudi romskih skupnosti, ki morajo biti pripravljene, da se integrirajo, pripravljene, da začnejo živeti na normalen način v družbah, v katere so se odločili priti [...] Otroke je treba spraviti v šolo, da bo lahko naslednja generacija Romov živela normalno življenje.

V imenu integracije je upravičljivo marsikaj: pripisovanje motnje v duševnem razvoju, prikazovanje romskega okolja in kulture kot »nenormalne « v razmerju do večinske družbe, grožnje odvzema socialne podpore zaradi absentizma otroka v šoli, ki je pogosto edini vir dohodka družine, segregacija romskih otrok v posebnih oddelkih vrtcev in šol, jemanje otrok od pouka, da »bodo nadoknadili zaostanek«. Novak (2006, str. 272) je v članku »Vrtec v romskem naselju « zapisala:

Ključna prva faza integracije pa je zagotovitev večje izobrazbe Romom. Ravno neizobraženi (in nezaposleni) Romi so poglavitna ovira pri reševanju romske problematike. Če bo segregacija romskih otrok z večjo represijo in z reševanjem problema prevelike rodnosti Romov prinesla boljše rezultate, potem ni to nič slabega. Ko se bo ustvarila dovolj velika kritična masa izobraženih Romov, takrat se bodo zadeve pospešeno spreminjale na boljše.

Za konec ugotavljam, da lahko tudi nereflektirano »vključevanje« Romov poraja nove etape izključevanja, diskriminacije in rasistične obravnave, ker ohranja simbolno mejo med Nami in Njimi čvrsto. Tako se zdi, da je težava predvsem nerazvitost Romov, ne pa antiromski rasizem, socialno-ekonomska prikrajšanost, diskriminacija, segregiranost. Poznavanje konteksta, v katerem se porajajo vneti poskusi »vključevanja«, je ključno za razumevanje (ne) uspeha evropskih, nacionalnih, občinskih, šolskih, vrtčevskih projektov, ki si za objekt jemljejo Rome.

Pri iskanju rešitev za zgodovinsko določene in strukturne neenakosti se je treba ogniti ideji, da lahko te premagamo $\mathrm{z}$ več istega - $\mathrm{z}$ več vzgoje, izobraževanja, skrbi, socializacije, nadzora (z nespremenjenim idejnim ozadjem). Vztrajno vključevanje kljub vsemu ni pripomoglo k temu, da bi romski jezik postal učni jezik v javnih šolah, da bi bili romski otroci ob vstopu v izobraževalne institucije deležni pouka slovenščine (kot drugi tujejezični otroci) in da bi se izboljšal njihov materialni in nastanitveni položaj. Za zdaj so projekti vključevanja, kot zapiše Maeso (2014, str. 60), »civilizirajoče misije, katerih namen je popraviti patologiziran način (romskega) življenja«. 
Stroke, ki rešujejo »romsko problematiko«, hkrati ustvarjajo vednost o Romih (Simhandl, 2006), predvsem pa vednost o Romih kot o problemu (Fejzula, 2019). Romi s tem postanejo ujetniki enopomenske kategorizacije, v kateri so reprezentirani kot deficitarni, odklonski, ranljivi in v srži drugačni od večine (Maeso, 2014). Z vsemi simbolnimi (in materialnimi) sredstvi so distancirani od vsega, kar imamo za normalno. Šele ta pompozna »nenormalnost « namreč poganja strokovni aparat »vključevanja«. Šele ko je konstrukt izključenega/ranljivega/deficitarnega Roma proizveden, ga je moč udejanjati v posameznih strokovnih kontekstih. Šele takrat je mogoče utemeljiti vzgojne in skrbstvene manevre, s katerimi naj »se izboljša « romsko (biopolitično) eksistenco. Pri vsem tem pa se pozablja, da »socialno vključevanje ne pomeni, da kdo ,ustreza' večini ali pa da je vključen kot «izjemas, temveč da se razširjajo norme normalnosti « (Zaviršek, 2003, str. 223). Strokovni delavec mora torej poznati svoje mesto v kontinuiteti izključevalnih in vključevalnih postopkov in prepoznavati možnost, da so tudi pozitivne prakse strokovnjakov vpete $\mathrm{v}$ mehanizme reprodukcije strukturne neenakosti in simbolnega nasilja - čeprav vzbujajo vtis miroljubne legitimnosti, saj potekajo v imenu »reševanja Romov pred njimi samimi« (Maeso, 2014, str. 60).

\section{Viri}

Agamben, G. (2013). Izjemno stanje. Homo Sacer II, 1. Ljubljana: Založba ZRC SAZU.

Balibar, E., \& Wallerstein, I. (1998). Race, nation, class. London, New York: Verso.

Boljka, P., \& Krnjić, S. (2006). Cigani/Romi v knjigah znanja: podoba ciganske/romske kulture in načina življenja v enciklopedijah. V B. Jezernik (ur.), » Zakaj pri nas žive Cigani in ne Romi « - narativne podobe Ciganov/Romov. Ljubljana: Oddelek za etnologijo in kulturno antropologijo, Filozofska fakulteta, Univerza v Ljubljani.

Burman, E. (2008). Developments: child, image, nation. London, New York: Routledge.

DiRicchardi-Muzga, R. (2011). Tudi Bog je umaknil svoj pogled od Ciganov/Romov: Berša bibahtalipe Romenghere: Naci holokausta. Ljubljana: Društvo Romski informacijski center Slovenije Anglunipe.

Dragoš, S. (2005). Multikulturalizem - rešitev ali problem? V V. Leskošek (ur.), Mi in oni (nestrpnost na Slovenskem) (str. 41-81). Ljubljana: Mirovni inštitut.

Duffield, M. (2007). Development, security and unending war. Cambridge: Polity.

Duffield, M. (2010). The liberal way of development and the security-development impasse. Security Dialogue, 41, 53-76.

Duffield, M., \& Waddell, N. (2006). Securing humans in a dangerous world. International Politics, 43, 1-23.

Evropska komisija (2014). Report on the implementation of the EU Framework for National Roma Integration Strategies. Bruselj: Evropska komisija.

Fejzula, S. (2019). The anti-Roma Europe: modern ways of disciplining the Roma way in urban spaces/ A Europa Anti-Roma: Formas modernas de disciplina do corpa Roma nos escapos urbanos. Coimbra: Universidade de Coimbra.

Ferguson, N. (2012). Civilization: the West and the rest. New York: Penguin Books.

Fraser, A. (1995). The Gypsies. Oxford, Cambridge: Blackwell.

Gjerkeš Ščančar, S. (2016). Bralna pismenost Romov v maternem in slovenskem knjižnem jeziku (magistrsko delo). Maribor: Pedagoška fakulteta, Univerza v Mariboru.

Goldber, D. (2015). Are we all postracial yet? Cambridge: Polity. 
Intervju (2019a). Intervju s svetovalno delavko v osnovni šoli. Ljubljana: osebni arhiv. Intervju (2019b). Intervjuji z ravnateljico vrtca. Ljubljana: osebni arhiv.

Ivanov, N., \& Medved, L. (2006). Podobe cigana v Slovenskih večernicah. V B. Jezernik (ur.), Zakaj pri nas žive Cigani in ne Romi: narativne podobe Ciganov/Romov (str. 7-33). Ljubljana: Oddelek za etnologijo in kulturno antropologijo, Filozofska fakulteta.

Janko Spreizer, A. (2001). Socialnoantropološki pogled na slovensko romologijo. Monitor ISH, III(1-2), 29-63.

Janko Spreizer, A. (2002). Vedel sem, da sem Cigan - rodil sem se kot Rom: znanstveni rasizem v raziskovanju Romov. Ljubljana: ISH - Fakulteta za podiplomski humanistični študij.

Katz, C. (2004). Growing up global: economic restructuring and children's everyday lives. Minneapolis, London: University of Minnesota Press.

Koretič, M. (2007). Poročilo: aktivnosti za integracijo romskih otrok v vrtec Leskovec - realizacija, izkušnje, ugotovitve in predlogi za 2007/2008 (str. 4-6). Leskovec pri Krškem: Vrtec Leskovec pri Krškem.

Krašovec, P. (2015). Rasizem, odvečnost, begunstvo. Borec: revija za zgodovino, literaturo in antropologijo, 67(721/723), 8-22.

Krek, J. (ur.) (1995). Bela knjiga o vzgoji in izobraževanju v RS. Ljubljana: Ministrstvo za šolstvo in šport.

Liégeois, J. P., \& Gheorghe, N. (1995). Roma/Gypsies: a European minority. Minority Rights Group International Report 95/4.

Lucassen, L., Willems, W., \& Cottar, A. M. (1998). Gypsies and other itinerant groups: a socio-historical approach. London: Palgrave Macmillian.

Maeso, S. R. (2014). »Civilising « the Roma? The depoliticisation of (anti-)racism within the politics of integration. Identities, 22(1), 53-70.

Mayall, D. (2004). Gypsy identities 1500-2000: from Egipcyans and Moon-men to the ethnic Romany. London, New York: Routledge.

Merhar, B. (2016). Učinkovitost vzgojnih dejavnosti in ukrepov pri populaciji romskih učencev po vzgojnem načrtu (diplomska naloga). Ljubljana: Pedagoška fakulteta, Univerza v Ljubljani.

Miladić, D. (2012). Integracija romskih otrok v vrtec kot napovednik uspešnosti v šolstvu (diplomska naloga). Ljubljana: Pedagoška fakulteta, Univerza v Ljubljani.

Novak, M. (2006). Vrtec v romskem naselju: vzgaja, uči in živi ... Sodobna pedagogika, 57(123), posebna izdaja.

Olivera, M. (2012). Strokovna fabrikacija »romskega vprašanja « - prepletenost multikulturalizma in neoliberalizma. Časopis za kritiko znanosti, 247(1/4).

Powell, R., \& H. van Baar (2019). The invisibilization of anti-Roma racisms. V H. van Baar, A. Ivanusic, \& R. Kreide (ur.), The securitization of the Roma in Europe (str. 91-113). New York: Palgrave Macmillan.

Projekt skupaj do znanja (b. d.). Pridobljeno 22. 2. 2021 s https://www.padeznik-mojasola.si/ portfolios/projekt-skupaj-do-znanja-2/\#

Repič, J. (2006). Medkulturni dialog med Romi in civili kot strategija izključevanja. V B. Jezernik (ur.), » Zakaj pri nas žive Cigani in ne Romi « - narativne podobe Ciganov/Romov. Ljubljana: Oddelek za etnologijo in kulturno antropologijo, Filozofska fakulteta, Univerza v Ljubljani.

Ringold, D., Orenstein, M. A., \& Wilkens, E. (2003). Roma in an expanding Europe: breaking the poverty circle. Washington, DC: The International Bank for Reconstruction and Development.

Simhandl, K. (2006). »Western Gypsies and Travellers « - » Eastern Roma «: the creation of political object by the institution of the European Union. Nations and Nationalism, 12(1), 97-115. 
Sovič, N. (2010). Romi v slovenskem vzgojno-izobraževalnem sistemu (primer OŠ Bršljin) (diplomsko delo). Ljubljana: Fakulteta za družbene vede, Univerza v Ljubljani.

Strategija EU o vključevanju Romov (2011). Pridobljeno 22. 2. $2021 \mathrm{~s} \mathrm{https://eur-lex.europa.}$ eu/legal-content/SL/TXT/PDF/?uri=CELEX:52011/P0092\&from=ET

Strategija reševanja romske problematike v Občini Krško za obdobje 2018-2022 (2018). Pridobljeno 22. 2. $2021 \mathrm{~s}$ https://www.krsko.si/files/other/news/71/149925Romska\%20 strategija.pdf

Strategija vzgoje in izobraževanje Romov v Republiki Sloveniji (2004). Dosegljivo 22. 2. 2021 s: http:/www.romsvet.si/doc/Zakonodaja/Strategija\%20vzgoje\%20in\%20izob\%20 Romov_2004.pdf

Šiftar, V. (1970). Cigani: minulost v sedanjosti. Murska sobota: Pomurska založba.

Šumi, I. (2000). Kultura, etničnost, mejnost: konstrukcije različnosti v antropološki presoji. Ljubljana: Založba ZRC SAZU.

Tancer, M. (1994). Vzgoja in izobraževanje Romov na Slovenskem. Maribor: Založba Obzorja.

Trubeta, S. (2013). Roma as homines educandi: a collective subject between educational provision, social control, and humanism. V M. Miskovic (2013), Roma education in Europe: practices, policies and politics. New York: Routledge.

UNDP (2002). The Roma in Central and Eastern Europe: avoiding the dependency trap. Bratislava: United Nations Development Programme.

Uspešno vključevanje Romov v vzgojo in izobraževanje (2012). Pridobljeno 22. 2. $2021 \mathrm{~s}$ http://www.osfpcrensovci.si/?page_id=376

van Baar, H. (2018). Contained mobility and the racialization of poverty in Europe: the Roma at the development-security nexus. Social Identities, 24(4), 442-458.

van Baar, H. (2019). From » lagging behind « to » being beneaths «? The de-developmentalization of time and social order in contemporaty Europe. $\mathrm{V} \mathrm{H}$. van Baar, A. Ivanusic, \& R. Kreide (2019), The securization of the Roma in Europe. London: Palgrave Macmillan.

Young, R. J. C. (1995). Colonial desire: hybridity in theory, culture and race. London: Routledge.

Zaviršek, D. (2003). Notranja nasprotja socialnega dela pri uresničevanju človekovih pravic v postmodernih družbah. Socialno delo, 42(4/5), 219-230.

Zaviršek, D. (2010). Etnizacija in patologizacija Romov in romskih skupnosti: socialno-antropološki in socialnodelovni teoretski koncepti. Socialno delo, 49(2-3), 85-97.

Zaviršek, D. (2018). Skrb kot nasilje. Ljubljana: Založba /*cf.

Zaviršek, D., Djoković, N., Radešić, L., Meden, K., Đogić, K., \& Kožman, M. (2019). Romske družine: priročnik za razumevanje etične prakse v socialnem delu in drugih pomagajočih poklicih v podporo slovenskim Rominjam in Romom. Ljubljana: Društvo MOZAIK - društvo otrok. 
